American Journal of Economics and Business Administration 3 (2): 390-400, 2011

ISSN 1945-5488

(C) 2010 Science Publications

\title{
The Wholistic Ethical Litmus of Leadership: A Practical Non-Linear Dynamics and Chaos Based Leadership Model
}

\author{
${ }^{1}$ Lynn L. Adams and ${ }^{2}$ Nathanael L. Adams \\ ${ }^{1}$ Department of Business, Utah Valley University, \\ Woodbury School of Business, 800 West University Parkway, Orem, UT 84058, USA \\ ${ }^{2}$ Department of Business, Cardinal Stritch University, \\ College of Business and Management, 6801 N. Yates Road, Milwaukee, WI 53217, USA
}

\begin{abstract}
Problem statement: Management is generally easy to define and measure. And, good managers tend to have many of the same characteristics and skill sets. Great leaders, on the other hand, have fewer shared characteristics. Some great leaders are great orators, for example, and yet many other great leaders are terrible public speakers. Great leaders tend to be very intuitive, but other characteristics consistent with great leadership are few indeed. So, the authors of this study had a conversation over several years that led to the reduction of variables to two variables that immediately showed a pattern in individual leadership. Approach: This study presents a practical leadership matrix model based on non-linear dynamics and chaos theory. Specifically, the authors searched for two or more leadership variables (characteristics) that would create a definite pattern. The researchers intuitively believed that some combination of variables would set up a pattern just as attractors (strange or otherwise) create patterns in data and show some of the characteristics of the system being studied. Over time a set of two main variables, loosely labeled as ethics and energy at first, were identified that created a leadership pattern for individuals. This study describes the process that led to the identification of the two main variables and then to the matrix herein presented. Results: This model, called "The WELL" by the authors, was created at first to explain political leadership, yet is showing applicability to all kinds of leadership. The WELL as presented is a theoretical construct, with only experiential and qualitative evidence at present to support the patterns inferred from the model. Conclusion: In addition to the extensive political experience of the authors the experience of public safety, mental health, military and academic professionals has been sought to validate the main conclusions shown in this study and to improve the model.
\end{abstract}

Key words: Wholistic ethical litmus, leadership model, non-linear dynamics, chaos theory

\section{INTRODUCTION}

One of the most intriguing, valuable and, thankfully, simplifying concepts of Chaos Theory is that of "attractors" and "strange attractors"(Smith, 2007; Sprott, 2003). Attractors are the variables that set up particular and sometimes peculiar patterns in the behaviors of complex systems. For instance, patterns can be found in data images even though many variables may be involved, provided the right variables are picked to be graphed and, perhaps, if the images are looked at from a different view or angle. Chaos Theory relieves scientists or researchers from trying to graph and evaluate all the variables at the same time, which variables for an organization are almost infinite as every person in an organization is a variable. Instead, the task is to find a few variables that would reveal some patterns of leadership. Those attractor variables are the variables that will set up patterns that are visible and that give insight into what is going on in a much more complex reality.

The authors realize that using this approach to analyze leadership is unusual if not entirely new. They also know that the model shown in this study does not adhere to all of the characteristics of traditional attractors or strange attractors (Sprott, 2003). The desire was to find two variables of leadership that were also key variables for all great leaders, but were also variables that revealed new patterns in leadership not seen before.

The result of this study is a model named the WELL, or "the Wholistic Ethical Litmus of

Corresponding Author: Lynn L. Adams, Department of Business, Utah Valley University, Woodbury School of Business, 800 West University Parkway, Orem, UT 84058, USA Tel: 801-863-6483 Fax: 801-863-7314 
Leadership”. The inspiration for the name of the model came from the Chinese character for 'a well,' which looks roughly like a tic-tac-toe diagram and which represents the layout of a small town with a well in the middle [井].

Background: Writers and researchers of leadership, including the authors of this study, have been frustrated for many years over the reality that leadership is nebulous, if not "hazy," "intangible," and is full of "paradoxes" (Wren, 1995). Indeed, great leaders, overall, only share a small set of key characteristics, while possessing a wide variety of other great skills and abilities that are not common to all great leaders. However, this paradox of few shared characteristics among a larger number of available characteristics turns out to be a primer to help locate the attractor variables, if they can be called that, of leadership. The only shared characteristics of all great leaders of which the authors are aware are that great leaders are (1) life time learners, that is they are able to learn and to be taught (Burns, 1979), (2) have high levels of intuition (Bennis, et al., 1996; Burns, 1979) (3) have high energy (or strong work ethic) and (4) have a strong ethical base and values (O’Toole, 1996).

Not all scholars accept the last characteristic, ethics, on the aforementioned list. The debate hinges on whether leaders such as Hitler were great leaders or just great motivators, manipulators and deceivers. This last issue about leadership ethics is brought out in a unique way by the model presented in this manuscript. If the first three characteristics of great leaders, life long learners, high intuition and high energy/work ethic are accepted at face value as being common and critical to great leadership, then all that is left to discuss is why the ethics involved in the exercise of leadership is important to understanding leadership itself.

In analyzing political leaders and leadership the authors were intrigued by the question of what two key variables would clearly separate and delineate political leaders, as well as show a recognizable pattern that would help reveal leadership types. Despite not having much data to work with, other than the small list of shared characteristics shown above, the authors recognized a pattern in political leaders after reducing the variables to only two: ethics and energy. Closely tied to leadership energy is ability, but since available energy in a leader may or may not be due to ability, the decision at first was made to just evaluate leaders using the two variables of ethics and energy. Once these two variables were used to describe some political leaders known or studied by the authors, it was relatively easy to place past and present leaders onto the graph and to analyze their key characteristics. Curiously, studying those two variables, ethics and energy, led to other revealing patterns (similarities) and paradoxes between seemingly opposites on the graph that provided significantly deeper insights. These patterns will be covered later in the sections on the rows and columns of the WELL.

Energy or work ethic is as much a part of a person's overall ethical makeup as any other characteristic, such as honesty. Defending energy as a critical leadership characteristic is easy and obvious. However, arguing for other ethics, such as honesty, again, becomes problematic, not because honesty cannot be defended as an ethic, but because some could argue that in some critical leadership situations the end justifies the means, even when the tool is less than honest (Machiavellianism). Another paradoxical ethic is loyalty, which becomes problematic when not applied to the rules or requirements of the larger system. For instance, when a person is loyal to close friends but not to the law (in recondite old boy/girl networks in politics for example) loyalty turns into favoritism. Puzzling questions about how to split hairs with different ethics came up after discovering that the two characteristics, energy and general ethics, showed the distinct and revealing pattern in leadership that the authors were seeking. But, by sticking with the first two attractors uncovered in this research and by providing a continuum of ethics from totally Machiavellian to totally ethical and by not trying to sort through the problematic ethics that can be seen as good or bad, the authors have decided to abandon, for now, the tricky questions about specific ethics.

The two variables are laid out with a leader's work ethic, called energy, being the vertical axis, with Idle at the bottom and High Energy at the top. The second variable is on the horizontal axis with totally unethical (manipulators) on the left and highly ethical (servant leaders) on the right. Returning to the vertical or energy axis, many people have great raw talent to lead and to do many other things in life, yet are too slothful or scared to develop those skills beyond an initial natural advantage. These individuals would be placed near the bottom of the WELL. Also, many individuals work very hard, but lack the talent of others. Available energy in a leader is a blend of at least six abilities and tendencies identified by the authors. The vertical axis, which shows leadership energy, blends these abilities:

- Natural energy

- Physical ability

- Mental ability or cognition

- Specific situational skills 
- Courage

- Ability to influence

The nine types of leaders are composites and show a continuum on both scales. The model became more easily understood when the leadership types were given 'animal' names to represent the general characteristics of each leadership type. The Unethical High Energy became the "Wolf", the Ethical High Energy became the "Eagle", the Ethical Unable became the "Lamb" and the Unethical Idle became the "Hyena" (Fig. 1).

Once characteristics were defined the model seemed too uniform. Wolves, Eagles, Hyenas and Lambs are rare, while the Herd is very common. To solve this problem the model was revised to better reflect the population, where the Herd has the largest area, the Coyote, Horse, Bear and Hippo are second, then the Wolf, Eagle, Hyena and Lamb are smallest. This change is reflected in Fig. 2.

The three columns are distinct in just one significant way. The ethical side of the model is characterized by those who will try to be ethical no matter what the consequences. The unethical side includes those who have a victim mentality; either totally believed (Unethical Idle) or simply created to support a grand manipulation (Unethical High Energy). The middle column is torn between the two others. Thus, the middle column is much disturbed if not distorted, because these leaders are torn between ethical concerns and getting what they want. So, the main difference between the two sides and the middle is that the sides have made a definite choice to act in a more consistent manner-these people have made a choice to either be ethical or unethical, but the choice has clearly been made. The center is undecided. Of course the WELL shows a continuum between the two sides and the farther a person moves by their actions to one side or the other the more decided they are on either an ethical path or an unethical one. Some specific leadership traits tend to be consistent across each of the three rows of the WELL, remaining consistent across energy levels, so to speak.

People often have two distinct leadership styles depending on whether they feel threatened, pressured or stressed. Further, politicians and other leaders can tire in their office over time and lose energy, for many reasons. Age, burnout, being on too many committees, disillusionment, declining health, isolation (a real paradox for all types of leaders) and another tough election are just some of the many ways that leaders lose energy. The fall towards the comfortable mediocrity of the Mixed Ethics Normal Energy center of the WELL tends to create an inherent blindness in the leader, as they slowly equivocate and abandon their ethics and level of effort, seeing but not taking action on issues and problems they would not have allowed to slip in the past-apathy induced by position fatigue. This fatigue and the consequent drop in the energy level can happen to all levels of the model. Such fatigue can also result in a loss in ethics, where a person can shift from the right to the left, or simply make an unethical decision. To understand this relationship better the first characteristics described are the High Energy.

\begin{tabular}{|c|c|c|}
\hline $\begin{array}{l}\text { Wolf unethical } \\
\text { high energy }\end{array}$ & $\begin{array}{l}\text { Bear mixed } \\
\text { high energy }\end{array}$ & $\begin{array}{l}\text { Eagle ethical } \\
\text { high energy }\end{array}$ \\
\hline $\begin{array}{c}\text { Coyote } \\
\text { unethical } \\
\text { normal energy }\end{array}$ & $\begin{array}{l}\text { The herd } \\
\text { mixed normal } \\
\text { energy }\end{array}$ & $\begin{array}{l}\text { Horse ethical } \\
\text { normal energy }\end{array}$ \\
\hline $\begin{array}{c}\text { Hyena } \\
\text { unethical idle }\end{array}$ & $\begin{array}{l}\text { Hippo mixed } \\
\text { idle }\end{array}$ & $\begin{array}{c}\text { Lamb ethical } \\
\text { unable }\end{array}$ \\
\hline
\end{tabular}

Fig. 1: The WELL

\begin{tabular}{|c|c|c|}
\hline $\begin{array}{c}\text { Wolf } \\
\text { unethical } \\
\text { high energy }\end{array}$ & $\begin{array}{c}\text { Bear mixed } \\
\text { high energy }\end{array}$ & $\begin{array}{c}\text { Eagle } \\
\text { ethical high } \\
\text { energy }\end{array}$ \\
\hline $\begin{array}{c}\text { Coyote } \\
\text { unethical } \\
\text { normal } \\
\text { energy }\end{array}$ & $\begin{array}{c}\text { The herd mixed } \\
\text { normal energy }\end{array}$ & $\begin{array}{c}\text { Horse } \\
\text { ethical } \\
\text { normal } \\
\text { energy }\end{array}$ \\
\hline $\begin{array}{c}\text { Hyena } \\
\text { unethical } \\
\text { idle }\end{array}$ & $\begin{array}{c}\text { Hippo mixed } \\
\text { idle }\end{array}$ & $\begin{array}{c}\text { Lamb } \\
\text { ethical } \\
\text { unable }\end{array}$ \\
\hline
\end{tabular}

Fig. 2: WELL normally distributed 
Top row: High energy (Wolf, Bear, and Eagle): What follows is an explanation of the top row, of the WELL, starting with the Eagle. While each corner has interesting indications or characteristics, notice the similarities, opposites and strange paradoxes between each corner and the other corners to gain deeper insights into the model and leadership. All of the nine leadership types given with the model (Fig. 1) are very distinct leadership types. That is, people will attempt to lead with those characteristics; however, several of the identified leadership types are not leadership at all. Most leaders will fall on some continuum within the nine types, or will act near the line between two or more types within the model and will thus have some characteristics of several leadership types.

The eagle, ethical high energy: The Ethical High Energy is what many authors present as true leadership and has all of those key characteristics that make good leaders-a democratic style, ability to let go of power, high intuition, selflessness, not easily manipulated, vision, high energy, loyalty to the cause and to people. True Eagles are rare as are the other extreme corners of the model. The Eagle has high emotional intelligence, the ability to read others and their intentions and other key people skills, including all of the important leadership skills. Eagles are thus very intuitive.

What is surprising is that the Eagles can read others but they tend to be hard to read and to predict. Those two very powerful characteristics seem totally paradoxical given that an Eagle is a democratic leader and is direct with those that they lead (and all others for that matter). To quote Benjamin Disraeli, "Frank and explicit-that is the right line to take when you wish to conceal your own mind and confuse the minds of others". That being straightforward and direct hides an ethical leader's intents reveals that most people are not open, direct and honest; otherwise they would both understand and comprehend the ethical leader. But then a person has to be ethical or have once been ethical to understand a leader who is.

The Wolf or Unethical High Energy is also a hidden personality. The Wolf tries to hide who they really are until there is nothing that can be done to rid the world of them. The Eagle hides by being perfectly honest and open. Indeed the 1 . The shared and the conflicting characteristics of the Eagles and Wolves provide deep insights into these natural adversaries.

The Ethical High Energy Eagle leader is democratic by nature and derives power from the loyalty of followers, who in turn believe in both the vision and the person that is the Eagle. The more extreme Eagles are more ascetic in nature; that is, they are able to live in less than ideal conditions. Gandhi was very much an ascetic and led by his own personal suffering and simple living so that he suffered just as much or more than his followers. Great leaders derive much of their personal magnetism from allowing and even forcing themselves to suffer the same privations as their followers.

Eagles can only lead when the populace or group is amenable to their style of leadership. When a group of people are too unethical, the Eagles will not be allowed to lead, which leaves the door open for Bears and Wolves.

The wolf, unethical high energy: The most dangerous of all leaders, the Unethical High Energy have the energy, ability and charisma to cause and inflict great evil. Wolves are true Machiavellians and the most ruthless of manipulators. In their ruthlessness, Wolves are not true leaders in that their leadership is a manipulation, deceit and coercion. Fundamentally a monarchist, no matter the nature of their rhetoric, the Wolf is all about centralized power and control, to the point of being able to micromanage the group. Thus, in the end the Wolf is a self-appointed monarchist (dictator or king or queen), who will build an empire out of a centralized power structure, because that is the only power structure that will support an unethical and ruthless leader. Centralized power structures can also exist within so-called democratic power systems through behind the scenes manipulations, deceptions and combinations.

Obviously, Unethical High Energy leaders are totally selfish and, when they raise themselves to positions of power, are in fact self-appointed; no matter how carefully they manipulate appearances. Very audacious and self-assured, Wolves are power wielders whose prey, or desire, is power and an eternal legacy. The Wolf will, if given the opportunity, take the position of deity to secure their place as the source of power and worship. Wolves seek to control every aspect of the group's lives; they also require the adulation and worship, if not the fear, of their subjects. This creates a curious paradox: the Wolf is at the center of the universe wielding as much power as can be accumulated, as a result there are other Wolves who are constantly circling looking for the opportunity to strike and take over the position of master manipulator. The Wolf then is constantly looking around for enemies, some of them are real and some of them are fictitious. Nevertheless, all levels of society will pay for the great Wolves' paranoia. Where an Eagle will draw people to them and will never fear their followers, a Wolf will intentionally keep followers at bay and will be in 
constant fear of those they control. Both the Eagle and Wolf share charisma, high intuition, high energy and emotional intelligence. Those key four characteristics give them the ability to inspire others, while still cloaking their own thoughts, which in turn gives the Eagles and Wolves the ability to elevate the energy of their followers, to break and make inertia as needed and to both destroy and create organizational culture.

The Unethical High Energy leadership type also has what may be termed a true ascetic (ultra upper left corner). Maybe an ascetic in this case can only be measured by how ruthless the leader is; yet the difference between an ascetic Unethical High Energy and any other Unethical High Energy is critical to understanding how dangerous an Unethical High Energy Wolf can become. An ascetic Wolf will sacrifice anything, including any means to gain the power they seek. Many leaders, both ethical and unethical, have a hard time giving up their favorite means (wealth, the army, people, the firm) to gain the ultimate power they seek. Leaders often fall in love with their favorite means, which they wield to attain their position. The means is often an object of pride or love. The truly ascetic Unethical High Energy is able to sacrifice anything, including means such as people, an economy, national stability, wealth-anything, to gain their ultimate goal. Ascetic Eagles are also able to sacrifice that which they love when the situation calls for that sacrifice to preserve the greater good. The ascetic Wolf will sacrifice anything for power.

What the ruthless ascetic Wolf is able to give up can be the real illogical surprise to their adversaries and provides the strategic edge they may need to prevail. Part of the art of manipulation is being able to convince an opponent that a means will be dear enough to be retained when in fact it will be sacrificed to win. The sacrifice of all means can be the decisive move between an unethical and an ethical pair of competing people or revolutions and can possibly reduce or eliminate the strength of moral superiority. Thus, the ethical leader must be just as ascetic to have an equal chance to survive, all else being equal. Meanwhile, lesser Wolves may attempt to convince others that they are willing and able to sacrifice anything to achieve their ends.

The bear, mixed ethics high energy: The Wolf, Bear and Eagle share high energy and ability, but the center square of the top row, the Bear or Mixed Ethics High Energy is less similar to the corners than the corners are to each other. Some of the characteristics the Bear does share with the Wolf and Eagle are high intuition, high emotional intelligence, they are self-actualized, hard to manipulate and hard to read. The upper middle square is perhaps the most diverse set of individuals in the model because of the many different shades of ethics. The upper corners are more consistently the same or opposite of each other, while the middle square has an almost infinite number of combinations of characteristics from both sets of ethics, but not necessarily as extreme. Bears are survivors. They tend to set a pragmatic course that gets them what they desire in climbing to positions of power. However, their ethical flip-flops cause them to partially prostitute some of their own ethics to fit the situation and to get their desired aims. The Mixed Ethics High Energy leaders will match the compromised ethics of the firms they are climbing in, but often tend to stay away from more blatant ethical breeches, which could possibly lead to the loss of potential positions and in the worse case lead to prison time.

The Bear is an interesting category that includes a wide variety of characters. The reality is, however, that these people, like all three types in the middle column are partial prostitutes of ethics. These leaders have had to give up ethical ground in order to occupy the middle and must continue to do so to stay in the middle column, despite their ability and energy. These people, especially if they stay high energy for a long time, will age quicker than other leadership types. To occupy the middle ground of ethics is to be at war with oneself.

The inner turmoil created by being pulled ethically results in a loss in vision that sets the Wolf and the Eagle apart from the Bear. Both the Eagle and the Wolf have visions of the future for their followers, some great some terrible. The Bear has little to no vision and because of their years of bureaucratic fighting and promotions are prone to use tactics without regard to strategic considerations. This results in a leader who is ineffectual and who creates new organizations to solve simple problems. Normally, Bears do not last long as leaders mainly because the world is not a bureaucracy and people abhor the thought of their lives being run by one.

Middle row: Normal energy (Coyote, Herd, and Horse): What sets the upper row apart from the lower rows is their energy and good fortune of getting to the top. The ethics of each category varies considerably and it should be noted that the lines are arbitrary. All of the categories are continuous and not mutually exclusive and people can move up, down and side to side throughout their lives. The WELL, then, is a continuously dynamic model and these leadership changes would make sense for most people who tend to change through their life time. The next row of 
characteristics includes a set of people who are unable to reach to the top level.

Coyote, unethical normal energy: The Coyote, the Unethical Normal Energy, borrows from the column characteristics of the types above and below in the model and is best described as a leader with greater abilities and a greater work ethic than the Hyenas, which will be described below, yet not enough ability and energy to truly excel at being a master manipulator. The Unethical Normal Energy is totally selfish and the more to the left they slide, the more intense their selfishness. Yet they live in a precarious position. They are servants to Wolves, they are master to the Hyena and they prey off the Hippo, Herd and Bear. They are the mafia, the drug dealers, the pornographers, prostitution rings, con artists and the core leaders of many dark and seedy ventures. They are like parasites who live within a society and meet a need of an unethical faction of the middle group. Like a Coyote in the desert they live near and around man, knowing full well man can destroy them, but they persist in existing. They exist because the middle (Bear, Herd and Hippo) pay to allow them to exist.

Consider the examples of New Orleans and Las Vegas, two cities of sin and indulgence. Las Vegas has two great facades; the first is the study-thin mask of the casinos. The casinos look audacious and magnificent at a distance, yet upon closer scrutiny they are cheap and fake. The second and much more important illusion is the façade of chaos. When people go to Vegas they go for a good time, to gamble, catch a show and do things they never would do in their own town. At the same time people desire an element of security and control. Vegas has tapped into this need and created a place where people can go and be as wild and crazy as they wish but at the same time feel secure and safe. Armies of security and cameras everywhere make sure the chaos never gets out of hand. The safe chaos of Vegas can be considered an upper Coyote group who prey off people's vices for profit, but are sophisticated enough to know how to get the most money possible. This well managed façade is in sharp contrast to New Orleans.

New Orleans is similar to Vegas, especially during Mardi Gras, where people go in the thousands to indulge in the festivities. What sets New Orleans apart from Vegas is the lack of security and guards. The police do the best job possible, but New Orleans is chaos without normal constraints. If a partier wants to do something, there is a place for it to be done. Few limits exist to the chaos incurred in New Orleans. As Vegas exists near the upper side of the Coyote box, New Orleans is closer to the lower.
Often Coyotes have ambitions of being Wolves and several drug cartels have gained considerable power within their countries, to the point where they become quasi-wolves. The problem is their own internal conflicts prevent them from gaining that next level, as other members of the Coyote class try to do the same. A good comparison is a tank of crabs. Leave one in and it will get out. Put two in and even though the top is left uncovered, the crabs will drag each other down preventing either one from escaping. Assuming that the quasi-wolf does succeed in eliminating any challengers after years of cruel violence, they will still tend to rule in the same way, by violence and this results in more fear and chaos. The chaos works for the Coyote within their neighborhood, but for a ruling quasi-wolf too much chaos will mean revolt and removal from power.

Horse, ethical normal energy: The Horse or Ethical Normal Energy resembles the Unethical Normal Energy in their combination of energy and ability, but are diametrically opposite in personal ethics and in not being inherently selfish like the Coyotes. As a result the Horse does not rely on the Herd or the Coyote for support. The Horse and the Coyote will rarely meet unless there is a conflict between the two and then they are bitter enemies. Most of the trouble the Horse encounters is from the Herd.

The Herd dislikes the Horse because the Horse is what the Herd could be both ethically and in being true to themselves. The Herd could be as good as the Horse, but they chose the road of less ethics to go with the group as they seek security, whereas a Horse faces the insecurity. Horses are true to themselves and are true individuals. The Herd gives up their individuality for the mirage of security and companionship. When a member of the Herd meets a Horse who will not play Herd games, those who are part of the Herd instinctively lash out against them. Partially out of fear, but mainly out of guilt, the Herd punishes the Horse as the Horse shows what those in the Herd could be.

The Horses are great people who lack the ability to rise to the level of intensity of an Eagle. Horses have ambition, energy and ethics and like the Eagle also have vision. Horses understand that not everybody can be the leader, but they are no less important in their own sphere of influence. Their place may be as small as a few people they know and talk to; if that is their place then they have filled the measure of their existence. People tend to look for great people in great positions of leadership, of responsibility, of status. The Horses are an unsung group of leaders and influencers who live their lives in quiet contentment, knowing their place and being great in their role. No one should discount the contribution of those who are great in the small corners of life. These are the Horses of the world. 
Herd, mixed ethics normal energy: "I know thy works, that thou art neither cold nor hot: I would thou wert cold or hot. So then because thou art lukewarm and neither cold nor hot, I will spue [vomit] thee out of my mouth.” Revelations 3: 16.

Being in the middle of the model, the Mixed Ethics Normal Energy leader would seem uninteresting at first glance, but that is far from the case. Chaos Theory reveals something very interesting about the Herd. Attractors are often visualized as rivers and river basins and the area of indecision between strange attractors as the hills or divide between river basins. Water that falls will tend to be attracted to the basins and to the rivers, which is roughly similar to attractors. Attractors are "Dynamical systems in which, on average, line segments (or in higher dimensions, areas of volumes) shrink" to an area "completely inside itself..." (Smith, 2007). In short, an attractor tends to pull objects closer to them. The Herd in the middle is the attractor of the WELL.

Any normal logic and assumptions on how the Mixed Ethics Normal Energy Herd leaders really control what they do has to be dropped. Mixed Ethics Normal Energy leaders and those like them are both hard to predict and they do not control themselves or their decisions like they probably believe that they do. Mixed Ethics Normal Energy leaders are "wishywashy." Their projected control is an illusion. Mixed Ethics Normal Energy leaders are controlled by others and by circumstances much more than they realize, making them easy prey to manipulation. Indeed the longer the authors observed and reasoned on the characteristics of the middle of the WELL the more the realization strengthened that the Mixed Ethics Normal Energy type is defined by the corners of the model and that the Herd is living in what (Frankl, 1963) called the "Existential Vacuum".

The two axes of the model need to be seen as roughly a normal probability distribution with the greater number (percentage) of people clustering in the middle. Mixed Ethics Normal Energy leaders, then, are the intersection of the middle of two probability curves and most leaders will fall into this category, generally. The authors believe that the Mixed Ethics Normal Energy intersection of the two probability curves for ethics and energy is the leadership attractor. Translation: the middle of the model is where people tend to fall if they lose energy or ethics, while shying away from the inherent stress of criminality, laziness and attempting manipulation. The Herd is like a school of fish, where no one is in charge, but all the fish feel secure and comfortable while allowing the school to make decisions for them. However, unlike any real school of fish in nature, in the Herd a person is easier to manipulate and is more vulnerable while allowing the
Herd to influence their actions. People join the Herd to gain the illusion of protection.

One way to understand the Herd is to understand how they organize themselves. The Herd demands hierarchy, structure and groups. Some groups are the fad followers. Almost every month a new fad comes out: fashion, books, cars, investing, technology, video games and so on. The Herd will follow as many fads as they possibly can within their resources and will pour their hearts and souls into that fad. Why? For the single purpose of getting together with other fad followers so they can talk about that particular fad.

Once a person enters a Herd social group the first fad is great, because there is a sense of excitement, wonder and fulfillment as they get a momentary high. Yet the law of diminishing marginal returns creeps in and so as one fad loses appeal they have to replace it with another and another. Herd social groups often get to the point where they jump on every fad imaginable so they can talk to others and maintain their sociability. All the time they are losing themselves to the will of the Herd and they become lost in an imaginary matrix of self-delusion. Introverts, too, can be Herd members just as easily as extroverts and may have different motivations than socializing with a group.

Leaders in the Herd tend to be fad finders and positions holders, rather than effective leaders. Good leaders can fall into the Herd of leadership simply by burning out and starting to ignore some of the myriad of things that leaders face on almost a daily basis. Regular people who desire to become great leaders have to find their way out of the Herd, unless for some reason they were never in the middle to begin with.

As the authors named each of the leadership types the process was not too hard. Yet, naming the middle square was hard, until it was realized that in nature no animal would survive in the middle. The outside edge of the WELL marks the areas of specialization. Only humans exist in large numbers in the mediocre middle. Animals do exist in herds, but they still have special adaptations that help them survive. Herds, schools, flocks for animals provides protection. The authors believe that during times of high organizational or societal chaos that the Herd gets hit harder than any other group, because in stressful times a clear choice has to be made to go in one of two directions, either towards higher or lower ethics and either towards more or less energy to somehow deal with the chaos. Even under normal conditions the Herd is under pressure, because everyone around the Herd (the Bears, Horses, Hippos, Coyotes) are relying on the Herd and hence pushing and pulling them. The pressure on the Herd escalates under conditions of increased societal or group chaos. 
Bottom row: Idle (Hyena, Hippo and Lamb): The bottom row, Hyena, Hippo and Lamb, are easy to read, easy to predict, easy to manipulate and generally hard to elect or are unelectable. The bottom row is also lacking in intuition, a key leadership trait. The bottom row has street smarts, usually, but well developed intuition is more than street smarts. The bottom row cannot be lead.

Hyena, unethical idle: The Unethical Idle leader is an oxymoron. A Hyena is the epitome of the career criminal at the lowest levels. Hyena use any means to promote their desired lifestyle and laziness. The reason that an extreme Unethical Idle leader is rare is that laziness will tend to destroy other existing good traits that may otherwise develop into leadership in a person. The Unethical Idle corner is not leadership at all, only illogical, inefficient horse-trading, committing crimes that often take more time and energy than to earn a regular living. And, with those crimes comes the added risk of incarceration, injury and death. Gang affiliation, especially at the lower levels, is full of Hyenas.

Gangs attempt to create safety while committing crimes within a separate legal system. Often a gang is lead by a Coyote or at times a Wolf, but the lowest levels of gangs are always full of Hyenas. The Hyenas create a buffer to deal with the police forces and competing gangs. This way those who are in charge can lead in relative safety from the police.

The gangs lure members in by giving members a sense of belonging and family. For many Hyenas this affiliation is important because together they really can accomplish more than if they were alone. Some Hyenas do exist that are not members of a gang, mafia, or other organization. They are lone Hyena with the same laziness and unethical behavior.

The lamb, ethical unable: Originally, the lower right corner of the WELL was labeled as the "Ethical Idle", before the model was fully developed. No true examples of this type of leader were found. The Ethical Unable leadership type has all the innocence and goodness desired in a great leader, but not the ability to become or be one. In searching for people that fit the Ethical Unable corner of the model, it soon became apparent that unless a person is nearly totally unable to lead or incapable of action for some reason they could or would not be an "Ethical Idle" and that the label for this corner needed to be changed. The label was changed to the "Ethical Unable" and the realization was that this corner could only be occupied by mentally and/or physically challenged, innocent and childlike individuals.

Of the four corners of this leadership model, the Ethical Unable is the most rare in leadership positions, for reasons that should be obvious-even though innocent people exist and are not uncommon (down's syndrome would be one type), innocents are not elected and rarely are kept as monarchs. If retained as monarchs, the Ethical Unable type will usually be a puppet for unethical manipulators, kept for reasons of retaining the image of legitimacy. A notable exception was King George of Britain, who for a period of time contracted a disease that left him mentally incapacitated for several years. But, according to accounts of his life, King George was not idle or unable, just unable to lead for that time.

The hippo, mixed ethics idle: The Hippo or Mixed Ethics Idle is the Idle version of the Mixed Ethics and is not much of a leadership style (arguably an antileadership style), yet this type is just as common as the Bears. Very insecure and idle, the Hippo is the sideline critic. They love to point out what they see as wrong in leaders who are putting out effort to lead. Mixed Ethics Idle individuals want the power and the prestige without any real effort. They believe in leadership without any accountability, like the Unethical Idle type, but they shy away from outright crime generally. Hippos expect others to be accountable. Hippos like to lead from the sidelines and think that dictating orders is leadership. When their leadership fails to produce any results they immediately divert the blame onto someone or something else. Hippos are easy to avoid but can be dangerous, like their namesake. Working for this kind of person is pure hell. Working for a board of such people is unimaginable and unbearable. The personal prey of these individuals is often social recognition as well as power, so their decisions, howbeit in business, a club, service organization, or in politics will be reflected in their inability to work hard enough to earn or execute a position of power.

Hippos are like a troll under a bridge. They start with many great ideas, but in time get stuck in their own sloth. So, Hippos gravitate towards positions where they can 'guard the bridge', that is they are gatekeepers in positions where they do not have to work very hard, or are in positions where they perceive power. Harder working individuals who end up having to work through 'trolls' will find the situation frustrating. Hippos will demand things their way; failure to do so will result in not getting across the bridge. This strategy often backfires as those who are in positions of power and authority can and often do come down to remove these individuals from the company. One way to improve morale and efficiency of an organization is to find and remove the Hippos. To find the Hippos is as simple as saying their name to their co-workers, who will react by sighing, biting their lips, swearing under their breath, rolling their eyes, or exhibiting general distain. The Hippos are not a well 
kept secret in any organization, everybody knows who they are.

One might assume that the lower left corner types, the Unethical Idle, would be the most pitiful of the leadership types and ethically they are. However, in a strange way the Mixed Ethics Idle is more loathsome than any type in the model. The Hippos do not know who they are... at all. At least the criminal has made a choice as to their direction, not to glorify that unethical choice, yet their leadership style makes sense in that context. The Hippo's leadership makes no sense in any context. The only way to explain the Hippo's inability to lead is to realize that they are working on selfish ends only (personal prey), not on what is good for the group or the organization. Even a criminal's choices and attempts at leadership make more sense, because those choices are more consistent with their direction.

Leadership or management: One notable religious scholar made the argument many years ago that unethical leaders are not leaders at all but manipulators and managers. Like so many other titles that lose their luster with overuse, the term leader has suffered the ravages of being watered down to signify anyone in charge. The term manager, too, has also been diminished as nearly every worker in some fast food establishments now carry the appellation of manager, including those in charge of cleaning up after the customers. Not to disparage those who have to clean up after others or to do the other menial tasks and without further tarnishing the original and rightfully respected meaning of manager, the authors agree with Nibley that unethical leaders, especially those near the Unethical High Energy corner (Wolves), are unethical master manipulators who also have extremely good managerial skill sets, but not true leadership skill sets. Making the distinction between manager and leader in this case (and in all cases, actually) is crucial.

True leaders create and champion a vision that is open, not hidden and that inspires, energizes and mobilizes followers. Master manipulators set up a false vision or mirage that fools followers into thinking that they are supporting a grand new order. Usually, in the case of governments and even in other organizations, the manipulation includes a pretense to and an appearance of democracy and a higher set of ethics. John Boyd, the former Air Force Colonel who conceptualized and championed asymmetric warfare, formulated the equation used to design all US fighter aircraft since the F-16 and helped create the battle plan for the first Gulf War (see Patterns of Conflict online) also had deep insights into the issue of managers versus leaders, though he probably saw this problem from a different perspective. He identified the problem as deciding "to be [figure head/manager] or to do [leader/revolutionary]” (Coram, 2004).

What Boyd saw was that in order to make significant changes in large organizations, in his case the U.S. military and the Pentagon, a change agent within the system (he was a major at the time) usually had to choose whether to progress in the hierarchy by conforming to organizational norms (management...the road to becoming a general or CEO!), or to champion new ideas that threaten the status quo (the old boys and girls), but are necessary to reform constipated organizations. Boyd adroitly saw that the fundamental difference between most of the people that rise to the helm of large organizations (and many small ones) and the real change agents are simply that of "being or doing” (Coram, 2004). Boyd experienced what the authors have called the Thomas Paine Paradox first hand, first by not being promoted and second by being nearly kicked out of the military on several occasions. Boyd was absolutely correct in suggesting that those who do the hard change work in organizations usually get punished and even banished.

History is full of examples of this phenomenon and in many cases the ones who wanted 'to be' had very good people near them that wanted and were willing 'to do'. Still, the point is valid that someone or some organization has to do the hard work so that someone else can be somebody.

Master manipulators, Wolves, often stay in the shadows until everything is in place. By keeping out of the limelight until all is finished the Wolf leader presents no target for enemies. Additionally, a deception is so much easier to maintain if the change person or organization is not recognized or comprehended. If the organization is not perceived then it must not exist. In the case of unethical recondite organizations and revolutions the deception is usually best secured by the real manipulator-by keeping his/her identity secret until the outcome of a revolution is secured. Even master manipulators know when to do and when to be.

Mirages: Reality versus appearances: The authors have observed one last apparent pattern in a subset of people, which also can be shown using the WELL. Some leaders will change ethics when under pressure. The authors have long known about leaders who appear to be ethical, yet inexplicably turn to an opposite set of values and ethics under duress. One author, who cannot be recalled at present, stated that some leaders have two sets of ethics, one when times are normal and another when stress and/or chaos is high in their lives. The question is whether these people who seem to switch to an opposing and opposite set of ethics under pressure 
are genuine before stress causes them to suddenly change ethics, or if the former self was as only a show. The authors are unsure, but tend to think that in many cases these kinds of individuals want to make others believe that they are more ethical than they really are inside. If so, then some level of stress or chaos will 'reveal' the true set of ethics and the true self. In this case the change of ethics is from what appears to be relatively strong ethics too almost the exact opposite.

In another group of individuals the transformation of ethics is from what appears to be a less ethical state to a higher ethical state under pressure, stress or chaos. This second group likes to put on a show of being 'tough' or less ethical when in fact the true self is really ethical. This deliberate contradiction is a way to avoid having to deal with insincere people who are putting on the exact opposite show described above.

\section{Limitations:}

The danger in obsessing about individuals: "When you try to fix your eyes on some particular point, there is a sense of distraction and this becomes what is known as an affliction in martial arts" (O'Toole, 1996). Robert Greene, too, warned in his book on war strategies about holding on to "fetishes" and allowing our minds to be "obsessed" with various concerns, such as "winning", using a specific weapon/tool, or "attacking" (Greene, 2007). The same is true for obsessing about individuals. That is, in applying the WELL a person or an entire group can become too focused on specific individuals (or groups), especially their enemies and lose sight of the bigger picture. Obsessing too much about unethical and evil individuals and organizations over time is easy to do, but will destroy a person's or an organization's peace and their objectivity. People in politics, law enforcement, the military and even in business, due to their day to day environments, often get to the point where they see all of society as evil. A former police officer admitted to the author that due to his particular police experience that he had to change careers, because in his words, "I had gotten to the point where I believed that everyone, or at least 97 percent of everyone, was a butt-head" (Duane Neyens, 2010, personal interview). Obsessing about rivals or enemies to the exclusion of other creative and positive thoughts will destroy a leader. Leaders must let go. Deal with and face up to the unethical and manipulative, yes. Obsess, no.

Obsessing about great leaders, however, is a good thing. In hard to read. To study and to try to become as
Eagles are requires the ability to see them in the first place. The WELL helps by outlining the Ethical High Energy's general characteristics. In ethical organizations Eagles will be out in the open and near or at the top of the organization. In unethical institutions and organizations, Eagles will either be hidden or missing. Huang Shih-kung's words of many centuries ago seem a haunt:

"...perfected man perceive the sources of flourishing and decline, understand the beginnings of success and defeat, have attained true knowledge of the crux [chi] of governing and turbulence and know the measure of coming and going. Such men, even in poverty, will not hold a position in a doomed state. Though lowly, they will not eat the rice of a turbulent country. They conceal their names and cling to the Way [Tao]. When the proper time comes they move, reaching the pinnacle, which a subject can attain. When they encounter Virtue that accords with them, they will establish extraordinary achievements... their names will be praised in later generations (Sawyer and Sawyer, 1993).

With almost every tool comes the ability to harm. The WELL also can be used as an effective evaluation tool or can turn into an obsession towards others that harms the person using the model. Oftentimes, the better the tool the greater the potential harm, both to others and to the person wielding the device.

The WELL and reflexivity: In general, the WELL is not that effective in evaluating oneself. While knowing oneself is a critical part of being an effective leader and while the WELL may seem convenient for selfevaluation, the fact remains that using the WELL or any other leader evaluation model on oneself is problematic. In the humble opinion of the authors the best way to use the WELL is to find and evaluate great leaders and then to try to gain the characteristics of those leaders over time. A person who tries to evaluate himself or herself will generally either overstate their position on the grid, or they will be too hard on themselves. A safe bet would be that anyone who brags about or presents themselves as being an Eagle or a Wolf needs to be watched. They will exaggerate about other things, too...

The one method of self-evaluation suggested in the WELL that shows some objectivity is to observe and study one's natural enemies. In many leadership arenas a person will attract enemies, even when doing the right things for the right reasons. So, despite good leadership a leader will find enemies along the way and those 
adversaries will be roughly a mirror image of the leader. The more ethical the leader the more unethical that person's natural enemies will tend to be and vice versa.

\section{CONCLUSION}

The WELL as presented in this study is a theoretical construct built on principles of chaos theory and especially attractors. The WELL is very much a deviation from the current literature on leadership and thus is only vaguely reflected in other writings. The WELL is easy to understand, intuitive and seems familiar, yet the model is sufficiently complex to warrant this study just to get this model explained and out into the field of leadership without the usual data.

The next step and series of research projects suggested by this study and the WELL would be to quantify the model and refine the nine leadership types and the characteristics of each. Additionally, the authors want to investigate the effect of culture on the distribution of people within the WELL and how the distribution may be distorted in failing societies, groups and organizations.

The WELL has shown many obvious patterns and relationships so quickly and intuitive to understand that the authors felt compelled to release the WELL without the usual large data sets to back up what the model is showing. In the future more variables may be identified which add to the WELL, or that work with one of the two variables identified in the WELL, or that show patterns completely separate from the WELL. The unique approach used to find the WELL may be more important than the model itself. If most of the relationships and patterns suggested by the WELL hold up to hard data and careful study then this model will be a significant leap in the understanding and application of leadership principles.

\section{REFERENCES}

Bennis, W.G., J. Parikh and R. Lessem, 1996. Beyond Leadership: balancing Economics, Ethics and Ecology. 2nd Edn., Blackwell, UK., ISBN-10: 155786960X, pp: 368.

Burns, J.M., 1979. Leadership. 1st Edn., Harper and Row Publishers, New York, ISBN: 10: 0060906979, pp: 530.

Coram, R., 2004. Boyd: The Fighter Pilot Who Changed the Art of War. 1st Edn., Boston: Little, Brown and Company, New York, ISBN-10: 0316796883, pp: 504.

Frankl, V.E., 1963. Man's Search for Meaning: An Introduction to Logotherapy. 3rd Edn., Beacon Press, New York, ISBN-10: 0807014265, pp: 154.

Greene, R., 2007. The 33 Strategies of War. 1st Edn., Profile Book, USA., ISBN-10: 1861979789, pp: 471.

O’Toole, J., 1996. Leading Change. The Argument for Values-Based Leadership. 1st Edn., Ballentine Books, New York, ISBN-10: 0345402545, pp: 304.

Sawyer, R.D. and M.C. Sawyer, 1993. The Seven Military Classics of Ancient China. 1st Edn., Basic Books, China, ISBN: 10: 0465003044, pp: 592.

Smith, L.A., 2007. Chaos. A Very Short Introduction. 1st Edn., Oxford University Press, New York, ISBN: 10: 0192853783, pp: 180.

Sprott, J.C., 2003. Chaos and Time-Series Analysis. 1st Edn., Oxford University Press, New York, ISBN10: 0198508409, pp: 507.

Wren, J.T., 1995. The leader's Companion. Insights on Leadership through the Ages. 1st Edn., Free Press, New York, ISBN: 10: 002874005X, pp: 554. 